Review

\title{
Multifaceted Mechanisms of Areca Nuts in Oral Carcinogenesis: the Molecular Pathology from Precancerous Condition to Malignant Transformation
}

\author{
Yi-Chen Li1 ${ }^{*}$, Ann-Joy Cheng2,3*, Li-Yu Lee4, Yu-Chen Huang5, Joseph Tung-Chieh Chang $3,6, \bowtie$ \\ 1. Division of Cardiology, Department of Internal Medicine, Kaohsiung Chang Gung Memorial Hospital and Chang Gung University College of Medicine, \\ Kaohsiung 833, Taiwan. \\ 2. Department of Medical Biotechnology and Laboratory Science, College of Medicine, Chang Gung University, Taoyuan 333, Taiwan \\ 3. Department of Radiation Oncology, Chang Gung Memorial Hospital-Linkou, Taoyuan 333, Taiwan \\ 4. Department of Pathology, Chang Gung Memorial Hospital-Linkou, Taoyuan 333, Taiwan \\ 5. Department of Oral Maxillofacial Surgery, Chang Gung Memorial Hospital-Linkou, Taoyuan 333, Taiwan \\ 6. Department of Radiation Oncology, Xiamen Chang Gung Memorial Hospital, Xiamen, Fujian, China \\ *First and second authors contributed equally \\ $\square$ Corresponding author: Joseph T Chang, Professor, Department of Radiation Oncology, Chang Gung Memorial Hospital-Linkou, Taoyuan 333, Taiwan. Fax:
} 886-3-2118247; E-mail: annjoycheng@gmail.com

(c) The author(s). This is an open access article distributed under the terms of the Creative Commons Attribution License (https://creativecommons.org/licenses/by/4.0/). See http://ivyspring.com/terms for full terms and conditions.

Received: 2018.09.06; Accepted: 2019.03.29; Published: 2019.07.08

\begin{abstract}
Oral cancer is one of the most frequent malignant diseases worldwide, and areca nut is a primary carcinogen causing this cancer in Southeast Asia. It has been widely reported that areca nut induced several cytotoxic effects in oral cells, including ROS generation, inflammation, tissue hypoxia, DNA damage, and cell invasion. Recently, through chronic exposure model, more extensive pathological effects due to areca nut have been found. These include the induction of autophagy, promotion of epithelial- mesenchymal transition, and facilitation of cancer stemness conversion. Clinical findings support these adverse effects. Oral submucosal fibrosis, a premalignant condition, is prevalent in the area with habitual chewing of areca nuts. Consistently, oral cancer patients with habitual chewing areca nut exhibit more aggressive phenotypes, including resistance to chemo-radiotherapy. In this review, we comprehensively discuss and concisely summarize the up-to-date molecular and cellular mechanisms by which areca nuts contribute to malignant transformation. This review may provide critical information regarding clinical applications in risk assessment, disease prevention, diagnosis, and personalized therapeutics for areca nut-induced oral malignancy.
\end{abstract}

Key words: areca nut, oral cancer, oral submucosal fibrosis, reactive oxygen species, tissue hypoxia, cell invasion, epithelial-mesenchymal transition, cancer stemness

\section{Introduction}

Oral cancer, including the common squamous cell carcinomas of the oral cavity and oropharynx, is the sixth most frequent cancer worldwide [1, 2]. The disease is more prevalent among males than females $[1,2]$. Epidemiologic studies have shown wide variations in its incidence in different geographical areas. Oral cancer is highly prevalent in Southeast Asia, comprising $35-40 \%$ of all malignancies in India, compared to approximately $9 \%$ in Taiwan and $2-4 \%$ in western countries [1-4]. The tumor sites of this disease differ in different geographical regions. Cancers of the tongue and buccal mucosa constitute the majority of oral cancers in India and Southeast Asia [1-4]. In contrast, the western regions show that cancers of the mouth floor are the most frequent, with cancer of the gums or tongue being rare [1-4]. Apparently, oral cancer also shows various clinicopathological features in different global regions.

The association of carcinogen exposure with oral cancer has been reported [3-5]. Carcinogens include 
habitual alcohol consumption, areca nut chewing, and cigarette smoking. Cigarette smoking and alcohol consumption are common habits in oral cancer patients in western countries. Cigarette smoking may render a significant carcinogenic effect on the upper aerodigestive tract, including oral areas [3-5]. Areca nut chewing is a common habit among oral cancer patients in Southeast Asia, indicating a close link of this habit with the specific disease. In Taiwan, for example, approximately $85 \%$ of all oral cancer patients are associated with this habit $[3,4]$. It has been shown that areca nut chewers have a much greater risk of developing oral cancer than nonchewers [3-6]. Furthermore, the 5-year survival rate of oral cancer patients who chew areca nuts is much lower than that of those who do not chew these nuts $[7,8]$. Therefore, the distinct clinicopathological characteristics of oral cancer in global regions may result from different environmental carcinogenic exposures in addition to genetic factors. In this paper, we comprehensively review and concisely summarize recent reports of the molecular and cellular effects of areca nuts that lead to the development of oral cancer.

\section{Molecular pathology of areca nut}

\subsection{Areca nuts are a primary carcinogen in Southeast Asia, with several active components}

Areca nuts have been one of the most commonly used psychoactive substances for a century, especially in Southeast Asia. For better chewing flavor in using, areca nuts are usually covered with piper betel leaves or inflorescence to form betel quids [3,4]. Areca nut extract is composed of saccharides (26-47\%), polyphenols $(11-26 \%)$, fats $(1.3-17 \%)$, various alkaloids (0.15-0.67\%), and some crude fiber and rare tannins [4-6]. Although alkaloids constitute only a few percent of all components, they are the most active ingredients associated with pathological development. Arecoline is the most abundant alkaloid, and it can be converted to arecaidine by salivary enzymes $[4,6]$. These alkaloids are converted to nitroso-derivatives, the primary inducers of oral mucosal lesions $[4,6]$.

In the past few decades, accumulated studies have demonstrated that areca nuts can induce premalignant and malignant transformation of oral tissues. In animal model studies, areca nut extract (or the ingredient cocktail) can be an effective tumor initiator or promoter and can induce premalignant oral lesions, including submucosal fibrosis $[9,10]$ and squamous hyperplasia [11-13], or result in malignant transformation [13-16]. For example, arecaidine displays a synergistic effect in the 7,12-dimethyl- benz(a)anthracene (DMBA)- induced tumor formation in the cheek pouch of hamster [15]. Similarly, combinational exposure of arecoline and 4-nitroquinoline-1-oxide (4-NQO) induces oral cancerous lesions in C57BL/6JNarl mice [11, 16]. Since the carcinogenic effect of areca nuts has become more visible, in 1992, the International Agency for Research on Cancer (IARC) announced that areca nut chewing combined with cigarette smoking is a human carcinogen. In 2004, IARC announced that the areca nut itself is a human carcinogen [17].

\subsection{Oral submucosal fibrosis is a common premalignant disorder induced by areca nut chewing}

The carcinogenesis of oral cancer is a multiple-step progressive process [6]. It is started from normal epithelial cells, gradually evolving to premalignant lesions. After malignant transformation, these cells eventually become aggressive types of cancers. Clinically, the premalignant oral disorders can be classified by distinct pathological features. These include hyperkeratosis, dysplasia, leukoplakia, erythroplakia, and fibrosis. Among these, leukoplakia is the most common disorder, while erythroplakia although rare, is more serious [18]. Both leukoplakia and erythroplakia are considered as premalignant lesions [18]. Oral submucosal fibrosis is a chronic progressive process, presenting an inflammatory fibrosis in oral mucosa stroma, being considered as premalignant condition [19-21]. This disorder is prevalent in India and Southeast Asia, a common premalignant condition caused by prolonged areca nut chewing [18-22]. Approximately $18 \%$ of the premalignant oral lesions will develop into squamous cell carcinoma [3]. Transformation of oral submucosal fibrosis may be variable, begin estimated between $2 \%$ to $8 \%$ and up to $13 \%$ [20-22].

The pathological effect of areca nut contributing to oral submucosal fibrosis is supported by several lines of studies. In a mouse model, the subcutaneous injection of areca nut extract-induced skin lesions and fibrosis [11]. This is accompanied with the expression of fibrotic marker proteins including alpha-smooth muscle actin (a-SMA) and connective tissue growth factor. In a cellular study, treatment of oral keratinocytes with arecoline upregulated the expression of av $\beta 6$ integrin and a-SMA to promote the formation of submucosal fibrosis [23, 24]. Treatment of fibroblast cells with areca nut extract also induced cell contraction mediated by several signaling pathways, including the JNK/ATF2/Jun axis, Ca2+/calmodulin axis, and Rho protein activation, leading to actin filament polymerization $[23,25]$. 
The accumulation of collagen is a notable pathological alteration in the patients with oral submucosal fibrosis [26]. In fibroblast cells, arecoline increased collagen expression by 1.5-fold [27], and this might result from elevating TIMP-1 and inhibiting gelatinase A activity [28]. Other areca nut components, such as flavonoids, catechins and tannins, facilitate the crosslinking of collagen fibers, resulting a decreased susceptibility to collagenase [29]. Increases in transforming growth factor $\beta 1$ (TGF- $\beta 1$ ) during areca nut-induced oral submucosal fibrosis has also been observed in many studies [10, $23,30]$. In the condition of submucous fibrosis, TGF- $\beta$ plays a critical role in regulating the degradation of the extracellular matrix, including collagen [31]. Consistently, it has been shown that arecoline augments collagen levels through the TGF- $\beta$ pathway in keratinocytes [32]. In summary, the areca nut promotes oral fibrosis by increasing collagen production, which may occur by various mechanisms, including reduction of degradation by proteinase and activation of the TGF- $\beta$ regulatory pathway.

The malignant transformation from oral submucosal fibrosis to squamous carcinoma involves multifactorial mechanisms. These include inflammation, genotoxicity, cytotoxicity, autophagy, tissue hypoxia, and epithelial-mesenchymal transition (EMT), as discussed respectively in the following sections.

\subsection{Chewing areca nuts increases ROS levels and induces inflammation}

Reactive oxygen species (ROS) are chemically reactive chemical species containing oxygen that can be generated during mitochondrial oxidative metabolism.

Under environmental stress, cellular ROS levels can become dramatically elevated and directly cause significant damage to cell structures at DNA, protein, or lipid levels [33]. Many studies have demonstrated that areca nuts can stimulate cellular ROS levels [34]. The mechanisms include the enhancement of ROS generation by mitochondrial metabolizing enzymes, such as cytochrome P450s (CYPs) [35], by the NADPH oxidase enzymes NOX-1 and NOX-4 [36], and the inhibition of antioxidant systems by the suppression of superoxide dismutase activities [37, 38].

The induction of ROS by areca nut extract has been further shown to act as a molecular signal to elicit redox-related inflammation or signaling pathways in many types of cells. For example, in endothelial cells, arecoline stimulates ROS production to suppress the expression of the cytoprotective enzyme hemeoxygenase-1 [39]. In lymphocytic cells, areca nut extract elicits oxidative stress and inflammatory responses and upregulates several cytokines, including NF-kB, Cox-2, PGE2, TGM2, and IL-1 [40]. Similarly, in fibroblasts and keratinocytes, areca nut extract or arecoline triggers ROS generation and induces tumor promoting mediators or oncogenic signaling pathways, including IL-6, TGF-b, EGFR, ERK and Ras [36, 41-43]. The different cytokines or signaling pathways in response to areca nut treatment may be cell type-specific. Clinically, the inflammation associated cells are increased in the surrounding tissues of oral submucosal fibrosis and oral cancers in the patients from areca nut chewing prevalent area [44]. In summary, areca nut extract may increase ROS levels, which facilitate cellular inflammation and tumor progression via multiple molecular regulators.

\subsection{Areca nuts may elicit genotoxicity, growth arrest, and apoptosis}

Many studies have demonstrated that areca nut extract exerts multiple cellular effects. Genotoxicity can be caused by areca nut exposure. The alkaloids of the areca nut are the major contributing factors to genotoxicity [6]. In oral keratinocytes or epithelial cells, areca nut extract or arecoline can induce genetic damage, including hyperdiploid chromosomal changes [45-47]. These DNA damage effects are associated with the inhibition of DNA repair mechanism, such as impairing p53 function [46, 47]. In a mouse model study, arecadine increased the frequency of sister chromatid exchanges during mitosis [48]. In a transgenic mouse study, arecoline increased the frequency of mutations at DNA G:C sites in oral tissue cells [49]. These genotoxic results are consistent with clinical findings in betel quid chewers. In the oral mucosal cells, the levels of chromosome damage, such as cytokinesis-block micronucleus, chromatid breaks or DNA strand exchanges, are positively correlated with habitual areca nut chewing in oral cancer patients [50-52]. Note that these cytogenetic alterations are less frequently observed in oral cancer patients who chew tobacco [51, 52].

Areca nuts may cause cytotoxicity in various types of human tissues and result in growth arrest, cellular senescence or apoptosis. In oral endothelial cells, arecoline induces G2/M cell cycle arrest and increases the sub-G0/G1 population, suggesting causal links among endothelial damage, vascularity reduction, and the pathogenesis of oral submucosal fibrosis [53, 54]. Similarly, in oral keratinocytes, epithelial cells, or neutrophils, areca nut ingredients or arecoline may contribute to G1/S cell cycle arrest, cellular senescence or apoptosis [37, 42, 55-59]. These effects may be caused by the activation of various signaling pathways, including Chk1/Chk2, 
MEK/ERK or AKT associated pathways $[42,59]$. The different cytotoxic effects and molecular pathways in response to areca nut stimulation may be dependent on specific cell types or the differential microenvironmental factors. In all, growth inhibition or cell suicide may be the optimal cellular defense mechanism to avoid further catastrophe of malignant transformation.

\subsection{Areca nuts may induce autophagy and inhibit tumor suppressors}

Although areca nut ingredients may lead to growth arrest and cell apoptosis, prolonged treatment with areca nut extract or arecoline may further facilitate malignant transformation. This is presumably via the induction of cellular autophagy or the inhibition of tumor suppressors. Autophagy is a process by which cells degrade unnecessary organelles and recycle intracellular proteins to ensure survival in adverse environments. Although autophagy may play dual roles in carcinogenesis, in most contexts, it promotes tumorigenesis [60]. The premalignant submucous fibrotic tissue or cancer cells may upregulate autophagy to survive microenvironmental stress and become more aggressive [4, 61]. Recent reports have shown that areca nut extract may induce autophagy via several pathways. For example, areca nut ingredients may be engulfed by oral cancer cells via clathrin-mediated endocytosis to initiate an autophagy program [62]. The other autophagy associated mechanisms, such as the LC3-II transition, Beclin-1 or Atg5 accumulation, and autophagosome formation, have also been demonstrated in oral cancer cells treated with areca nut extract [62-64]. The contribution of areca nut extract to autophagy may be explained by ROS generation or hypoxic condition in cancer cells, following the stimulation by various signaling pathways of PI3/AKT, MEK/ERK, AMPK/mTOR, or HIF-1a [63, 65-66]. Clinically, higher LC3 expression and poorer prognoses are found in advanced oral cancer patients who habitually chew areca nuts [66].

In addition to autophagy induction, areca nuts may inhibit tumor suppressor molecules to promote malignant transformation. It has been demonstrated that areca nut extract or arecoline may inhibit the expression of cell cycle checkpoint suppressors, including p53, p21, p27, and Ches1, which may enable cell cycle progression with error-prone DNA replication $[46,67,68]$. Clinical findings also support this concept. The reduced expression of the Ches1 suppressor has been found in oral cancer patients with the areca nut chewing habit [67]. In summary, the areca nut may contribute to cellular transformation by activating cellular stress response mechanisms, such as ROS generation, autophagy formation, and tumor suppressor inhibition.

\subsection{Area nuts may induce tissue hypoxia to promote malignant transformation}

Hypoxia is a low oxygen stress condition in tissue microenvironment, giving rise to altered cellular metabolism and triggers various pathophysiological responses [69]. This condition may be associated with the cellular oxidative stress $[65,69]$, and induce anaerobic respiratory pathway via up-regulations of hypoxia inducing factor (HIF), glucose transporter (GLUT), or lactate dehydrogenase [70-72]. Currently, hypoxia has been shown as an important underlying factor to promote tumorigenesis and cancer progression. It may incite several cellular mechanisms including autophagy, angiogenesis, epithelial to mesenchymal transition, cancer stemness, and lead to therapeutic resistance [73-74]. For examples, in oral submucous fibrosis, the tissue hypoxia resulted from vascular construction may further facilitate malignant transformation [20-22, 71]. Tissue hypoxia may further trigger EMT process via up-regulation of several transcriptional factors, such as Snail and Twist1, to promote tumor progression [75-76]. In cancer cells, the induction of HIF-1a molecule in the adaptation of hypoxic condition may elite angiogenic pathway via up-regulation of vascular endothelial growth factor (VEGF) [77]. Hypoxic condition in tumor microenvironment may also lead to therapeutic resistance by activation of stemness associated pathways, including Oct3/4, Sox2, and AKT/Notch1 molecular signals $[78,79]$.

The hypoxia inducing factor- 1 (HIF-1) is a predominant regulatory molecule induced by hypoxia tissue and emerges to malignant function [72, 73 , 77]. Recent reports have shown that areca nut causative to oral malignancy may associate with the hypoxic condition through the induction of HIF-1. In either oral fibroblast or oral cancer cells, arecoline may increase HIF-1a gene expression with a dose-dependent manner [80, 81]. In oral cancer cells, treatment of areca nut extract may induce ROS generation and up-regulate HIF-1a, which may further lead to autophagy to benefit cell survival [65]. The prolong treatment of areca nut extract in oral cancer cells results to a stronger tolerance in hypoxic condition via acquisition of autophagy and leads to chemoresistance [82]. Consistently, under a stress condition, areca nut extract induced VEGF expression in oral cancer cells, suggesting the mechanism of areca nut contributes to angiogenesis and cancer metastasis [83]. Clinically, higher levels of HIF-1a and PAI-1 have been found in the tissues of oral submucosa 
fibrosis or oral cancer cells compared to the normal mucosa [81, 84]. In summary, areca nut may incite tissue hypoxia to promote malignant transformation via multiple mechanisms.

\subsection{Areca nuts may promote cell motility and epithelial-mesenchymal transition}

Cell motility is an important characteristic of the malignancy response for cancer invasion and metastasis. In cells, the matrix metalloproteinases (MMPs) constitute a family of proteinases that degrade the extracellular matrix to accelerate cellular motility and invasion, whereas the tissue inhibitors of the metalloproteinases (TIMP) counteract this enzymatic activity. The areca nut contributes to oral malignancy by promoting cell motility as well. It has been widely reported that treatment with areca nut extract or arecoline can increase cellular migration, invasion or anchorage-independent growth in oral cancer cells, normal epithelial cells and fibroblast cells [85-91]. This response may result from the elicitation of MMP activities, including MMP-1 [80, 91], MMP-2 [81, 90], MMP-8 [85], and MMP-9 [59, 88, 89], and the suppression of TIMP functions [59, 92]. Multiple molecular signaling pathways, such as PI3K, p38 MAPK, Erk1/2, and NF-kB may be involved in the modulation of MMP and TIMP expression [87, 88, 93] and may through the muscarinic M4 receptor [93]. Clinical findings support this cell motility mechanism. High levels of MMP-1 or MMP-9 are found in the cancer tissues or saliva specimen of oral cancer patients who chewed betel nuts [85, 86, 93]. Apparently, the areca nut promotes cell motility through MMP activation, although different MMP proteins may respond differentially in different individuals.

The epithelial-mesenchymal transition (EMT) plays an important role in cell motility conversion leading to cancer aggressiveness [94-97]. The EMT confers tumor plasticity by transforming epithelial cells into spindle-like fibroblastic mesenchymal cells via functional loss of cell adhesion and the acquisition of migratory properties [94, 95]. This process involves disassembling cell-cell and cell-matrix junctions by downregulating epithelial markers (such as E-cadherin) and upregulating mesenchymal markers (such as N-cadherin) [94, 95]. It may be induced by several EMT/stemness associated transcription factors, allowing cells to gain stemness-related properties and create a pro-tumorigenic setting [96, 97]. Recent studies show that areca nut extract may induce oral fibrogenesis and carcinogenesis through EMT process. In buccal mucosa fibroblasts, areca nut extract or arecoline induces fibroblast trans-differentiation, which may be mediated by EMT associated transcription factors ZEB1, Twist, and Slug [98-100]. This fibrotic activity was found accompanying with collagen gel contraction, increase of marker protein expression (a-SMA), and elevation of migration capability [99, 100]. Similarly, in gingival fibroblasts or epithelial cells, areca nut stimulates fibrotic activation, preassembly through induction of EMT process via TGF- $\beta$ signaling pathways $[23,101$, 102]. Consistently, in either oral keratinocytes or cancer cells, areca nut facilitates EMT process, as shown by the increases of mesenchymal markers ( $\mathrm{N}$-cadherin, vimentin) and decreases of epithelial markers (E-cadherin, involucrin), via activating the PI3/AKT pathway [103, 104]. In oral epithelial or cancer cells, chronic or long-term treatment of areca nut extract facilitates mesenchymal trans-differentiation, along with the induction of multiple EMT associated transcription factors, including ZEB1, Snail, Slug, Twist, FOXC2, and Grp78 $[86,105,106]$. Furthermore, a keratin family member, Krt-17, was found to be upregulated by areca nut extract to facilitate cell motility and malignant transformation via EMT conversion in a mouse model study [11]. Clinically, the expression of EMT associated factor Slug has been found up-regulated in oral fibroblastic tissues and associated with various myofibroblast markers, such as a-SMA [99, 100]. The loss of E-cadherin expression and augmentation of Krt-17 or EMT-associated transcription factors have also been shown to be significantly associated with oral cancer in patients who habitually chewed betel quid $[11,86,107]$.

\subsection{Areca nuts may facilitate chemo-radioresistance and cancer stemness conversion}

Chemotherapy and radiotherapy are integral parts of the treatment for oral cancer. However, local recurrence after radio-chemotherapy is a major cause of therapeutic failure. Although areca nuts may elicit genotoxicity leading to cell death, recent studies showed that chronic areca nut exposure may eventually result in chemo- and radio-resistance. In oral cancer cells or normal keratinocytes, long-term exposure to arecoline or areca nut extract resulted in higher tolerance to cisplatin or fluorouracil $[82,86$, 105]. This areca nut-induced drug resistance may be attributed to overexpression of the ABCG2 protein, a well-known drug efflux pump in cancer cells [86]. Consistent with these reports, oral cancer cells chronically exposed to areca nut extract exhibited greater resistance to irradiation [86]. This survival advantage is accompanied by the reduction of ROS production by the elevation of the scavenger enzymes GCLC and GCLM [86]. Similarly, in keratinocytes, 
treatment with sublethal doses of arecoline upregulated the expression of multiple antioxidant enzymes, including G6PD, GCLC and glutathione reductase [108]. Clinically, the habitual use of areca nuts is an independent prognostic factor of poor survival of oral cancer patients receiving induction chemotherapy with docetaxel, cisplatin, or fluorouracil [8, 109]. The ERCC1 molecule, a critical DNA repair gene associated with chemoresistance, is up-regulated in oral cancer patients in the areca nut prevalent area [109]. Similarly, oral cancer patients who chew areca nuts habitually exhibit higher incidences of local recurrence [7]. Thus, chronic exposure to areca nuts facilitates chemo-radioresistance, which may due to the activation of cellular defense mechanisms to minimize the toxic damage in malignant transformed cells.

A cancer stem cell (CSC) model has been recently proposed to explain tumor heterogeneity. These cells, although comprise a small fraction within a tumor, possess a strong malignant potential, with self-renewal ability, stress tolerance, and high mobility, which results in aggressive cancer phenotypes and resistance to chemo-radiotherapy [110-112]. These types of stem-like cells are often characterized by specific surface proteins, such as CD44, CD133 and ALDH1, in oral cancer tissues [86, $113,114]$. Recent reports provide new insights that areca nuts may play a role in cancer stemness conversion. In oral cancer cells or normal keratinocytes, chronic areca nut exposure or long-term arecoline treatment facilitates the cancer stemness conversion. These were demonstrated by the enhanced spheroid cell formation and enriched subpopulations of CD24-/CD44+, CD133+, and ALDH1+ cells [86, 105]. Furthermore, these chronic areca nut exposures exerted a pluripotent effect to upregulate several stemness mediators, including

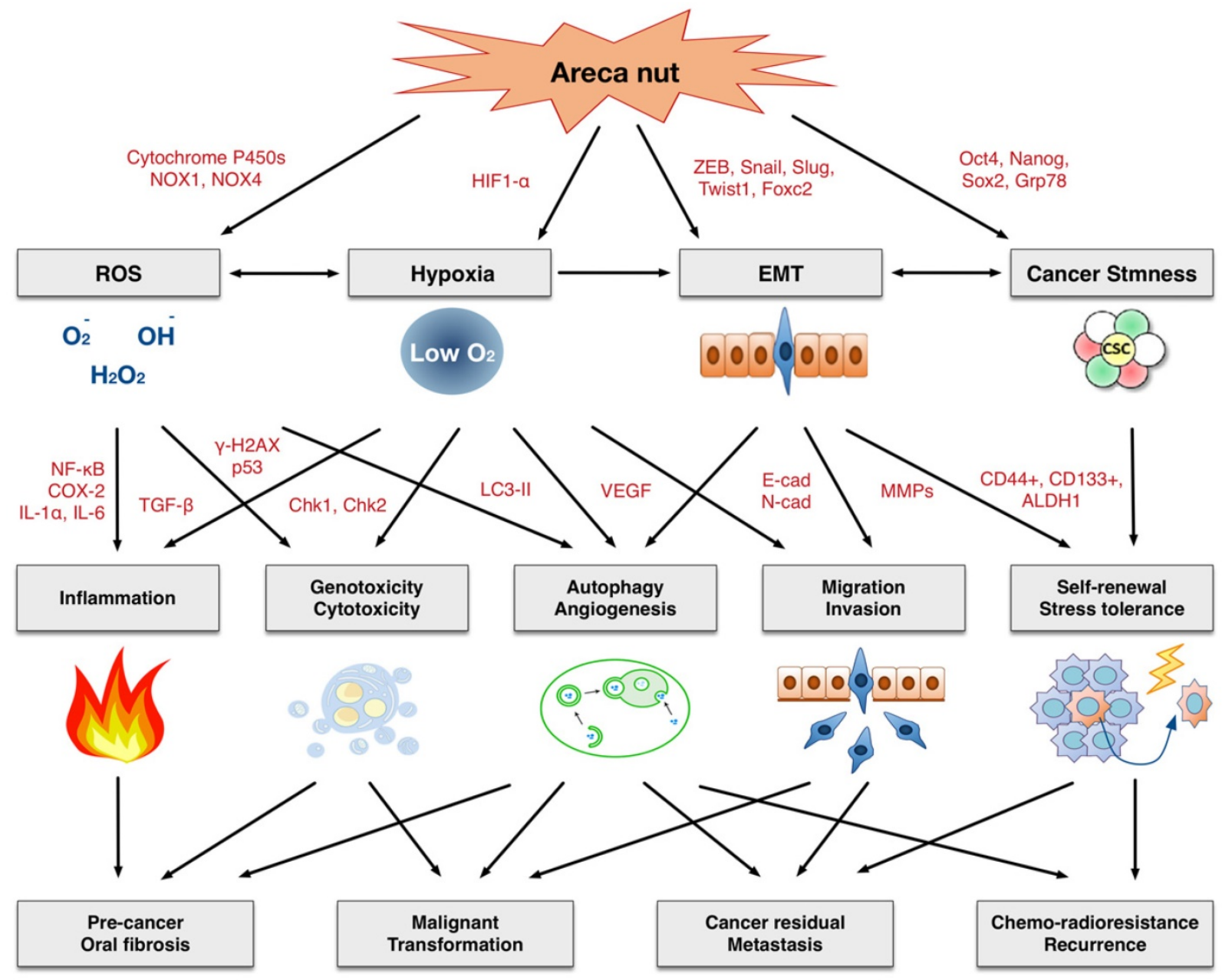

Carcinogenic Progression

Figure 1. Multifaceted mechanisms of areca nuts in oral carcinogenesis: the molecular pathology from precancerous lesions to malignant transformation. ROS: Reactive oxygen species. EMT: Epithelial-mesenchymal transition. 
Grp78, Slug, Snail, Oct4, Nanog, and Sox2 [86, 105]. This phenomenon is confirmed in clinical investigations. Oral cancer patients who habitually chewed areca nuts exhibited high levels of stemness regulators, such as Grp78 and snail, which was correlated with worse prognoses [86, 115, 116]. Consistently, oral cancer patients who habitually chewed areca nuts possessed cancers with more aggressive attributes, including higher incidences of second primary tumors, microsatellite residual tumors, and poor survival; all of which are characteristic of cancers with stemness properties [7, 117]. Thus, the areca nut contributes to malignancy by facilitating the conversion of CSCs via multiple stemness regulatory mechanisms.

\section{Conclusion}

In this review, we comprehensively discuss the underlying molecular and cellar mechanisms by which areca nuts contribute to malignant transformation. As summarized in Figure 1, the areca nut induces multiple cytotoxic effects, including inflammation, tissue hypoxia, DNA damage, autophagy, invasion, and chemo-radioresistance. These cellular effects are accompanied by numerous molecular alterations involving the production of reactive oxygen species, activation of various signaling pathways, promotion of epithelialmesenchymal transition, and facilitation of cancer stemness conversion. Clinical findings support these adverse effects. Oral submucosal fibrosis is prevalent in the area with habitual chewing of areca nuts. The oral cancer patients who habitually chewed areca nuts exhibited more aggressive cancer phenotypes, with higher rates of cancer metastasis, recurrence, and poor patient survival. Thus, areca nuts contribute to oral carcinogenesis via multifaceted mechanisms. This review may provide critical information for the risk assessment, disease prevention, diagnosis, and personalized or molecular therapeutics for clinical applications in areca nut-induced oral malignancy.

\section{Acknowledgments}

This work was supported by the grants from Chang Gung Medical Foundation (CMRPD1G0451 3, CMRPG3G1411 3) and Ministry of Science and Technology of Taiwan (MOST 106-2320-B-182025-MY3).

\section{Author Contributions}

YCL and AJC wrote the original manuscript; LYL and YCH participated in review of the paper, and JTC edited the paper. All authors have read and approved the final submission.

\section{Competing Interests}

The authors have declared that no competing interest exists.

\section{References}

1. Johnson NW, Warnakulasuriya S, Gupta PC, Dimba E, Chindia M, Otoh EC, et al. Global oral health inequalities in incidence and outcomes for oral cancer: causes and solutions. Adv Dent Res. 2011; 23: 237-46.

2. Saman DM. A review of the epidemiology of oral and pharyngeal carcinoma: update. Head Neck Oncol. 2012; 4: 1 .

3. Chen YJ, Chang JT, Liao CT, Wang HM, Yen TC, Chiu CC, et al. Head and neck cancer in the betel quid chewing area: recent advances in molecular carcinogenesis. Cancer Sci. 2008; 99: 1507-14.

4. Chen PH, Mahmood Q, Mariottini GL, Chiang TA, Lee KW. Adverse health effects of betel quid and the risk of oral and pharyngeal cancers. Biomed Res Int. 2017; 2017: 3904098

5. Sharan RN, Mehrotra R, Choudhury Y, Asotra K. Association of betel nut with carcinogenesis: revisit with a clinical perspective. PLoS One. 2012; 7: e42759.

6. Gupta B, Johnson NW. Systematic review and meta-analysis of association of smokeless tobacco and of betel quid without tobacco with incidence of oral cancer in South Asia and the Pacific. PLoS One. 2014; 9: e113385.

7. Liao CT, Wallace CG, Lee LY, Hsueh C, Lin CY, Fan KH, et al. Clinical evidence of field cancerization in patients with oral cavity cancer in a betel quid chewing area. Oral Oncol. 2014; 50: 721-31.

8. Su YY, Chien CY, Luo SD, Huang TL, Lin WC, Fang FM, et al. Betel nut chewing history is an independent prognosticator for smoking patients with locally advanced stage IV head and neck squamous cell carcinoma receiving induction chemotherapy with docetaxel, cisplatin, and fluorouracil. World J Surg Oncol. 2016; 14: 86.

9. Maria S, Kamath VV, Satelur K, Rajkumar K. Evaluation of transforming growth factor beta1 gene in oral submucous fibrosis induced in Sprague-Dawley rats by injections of areca nut and pan masala (commercial areca nut product) extracts. J Cancer Res Ther. 2016; 12: 379-85.

10. Chiang $\mathrm{MH}$, Chen $\mathrm{PH}$, Chen $\mathrm{YK}$, Chen $\mathrm{CH}$, Ho ML, Wang $\mathrm{YH}$. Characterization of a novel dermal fibrosis model induced by areca nut extract that mimics oral submucous fibrosis. PLoS One. 2016; 11: e0166454.

11. Chiang CH, Wu CC, Lee LY, Li YC, Liu HP, Hsu CW, et al. Proteomics analysis reveals involvement of $\mathrm{Krt17}$ in areca nut-induced oral carcinogenesis. J Proteome Res. 2016; 15: 2981-97.

12. Chang PY, Kuo TM, Chen PK, Lin YZ, Hua CH, Chen YC, et al. Arecoline $\mathrm{N}$-oxide upregulates caspase-8 expression in oral hyperplastic lesions of mice. J Agric Food Chem. 2017; 65: 10197-205.

13. Kuo TM, Luo SY, Chiang SL, Yeh KT, Hsu HT, Wu CT, et al. Fibrotic effects of arecoline N-oxide in oral potentially malignant disorders. J Agric Food Chem. 2015; 63: 5787-94.

14. Yeh CY, Chen HM, Chang MC, Kok SH, Lee JJ, Chang BE, et al. Cytotoxicity and transformation of $\mathrm{C} 3 \mathrm{H} 10 \mathrm{~T} 1 / 2$ cells induced by areca nut components. J Formos Med Assoc. 2016; 115: 108-12.

15. Lin LM, Chen YK, Lai DL, Huang YL. Minimal arecaidine concentrations showing a promotion effect during DMBA-induced hamster cheek pouch carcinogenesis. J Oral Pathol Med. 1996; 25: 65-8.

16. Chang NW, Pei RJ, Tseng HC, Yeh KT, Chan HC, Lee MR, et al. Co-treating with arecoline and 4-nitroquinoline 1-oxide to establish a mouse model mimicking oral tumorigenesis. Chem Biol Interact. 2010; 183: 231-7.

17. IARC Working Group. Betel-quid and areca-nut chewing and some areca-nut derived nitrosamines. IARC Monogr Eval Carcinog Risks Hum. 2004; 85: $1-334$.

18. Warnakulasuriya S. Clinical features and presentation of oral potentially malignant disorders. Oral Surg Oral Med Oral Pathol Oral Radiol. 2018; 125: 582-90.

19. Tilakaratne WM, Ekanayaka RP, Warnakulasuriya S. Oral submucous fibrosis: a historical perspective and a review on etiology and pathogenesis. Oral Surg Oral Med Oral Pathol Oral Radiol. 2016; 122: 178-91.

20. Arakeri G, Patil SG, Aljabab AS, Lin KC, Merkx MAW, Gao S, et al. Oral submucous fibrosis: an update on pathophysiology of malignant transformation. J Oral Pathol Med. 2017; 46: 413-7.

21. Ray JG, Ranganathan K, Chattopadhyay A. Malignant transformation of oral submucous fibrosis: overview of histopathological aspects. Oral Surg Oral Med Oral Pathol Oral Radiol. 2016; 122: 200-9.

22. Chattopadhyay A, Ray JG. Molecular pathology of malignant transformation of oral submucous fibrosis. J Environ Pathol Toxicol Oncol. 2016; 35: 193-205.

Pant I, Rao SG, Kondaiah P. Role of areca nut induced JNK/ATF2/Jun axis in the activation of TGF-beta pathway in precancerous oral submucous fibrosis. Sci Rep. 2016; 6: 34314.

24. Moutasim KA, Jenei V, Sapienza K, Marsh D, Weinreb PH, Violette SM, et al. Betel-derived alkaloid up-regulates keratinocyte alphavbeta6 integrin expression and promotes oral submucous fibrosis. J Pathol. 2011; 223: 366-77.

25. Chang MC, Lin LD, Wu HL, Ho YS, Hsien HC, Wang TM, et al. Areca nut-induced buccal mucosa fibroblast contraction and its signaling: a 
potential role in oral submucous fibrosis--a precancer condition. Carcinogenesis. 2013; 34: 1096-104.

26. Lin HJ, Lin JC. Treatment of oral submucous fibrosis by collagenase: effects on oral opening and eating function. Oral Dis. 2007; 13: 407-13.

27. Canniff JP, Harvey W. The aetiology of oral submucous fibrosis: the stimulation of collagen synthesis by extracts of areca nut. Int J Oral Surg. 1981; 10: 163-7.

28. Chang YC, Yang SF, Tai KW, Chou MY, Hsieh YS. Increased tissue inhibitor of metalloproteinase-1 expression and inhibition of gelatinase A activity in buccal mucosal fibroblasts by arecoline as possible mechanisms for oral submucous fibrosis. Oral Oncol. 2002; 38: 195-200.

29. Ekanayaka RP, Tilakaratne WM. Oral submucous fibrosis: review on mechanisms of malignant transformation. Oral Surg Oral Med Oral Pathol Oral Radiol. 2016; 122: 192-9.

30. Rehman A, Ali S, Lone MA, Atif M, Hassona Y, Prime SS, et al. Areca nut alkaloids induce irreparable DNA damage and senescence in fibroblasts and may create a favourable environment for tumour progression. J Oral Pathol Med. 2016; 45: 365-72

31. Anila Namboodiripad PC. Cystatin C: Its role in pathogenesis of OSMF. J Oral Biol Craniofac Res. 2014; 4: 42-6.

32. Thangjam GS, Agarwal P, Balapure AK, Rao SG, Kondaiah P. Regulation of extracellular matrix genes by arecoline in primary gingival fibroblasts requires epithelial factors. J Periodontal Res. 2009; 44: 736-43.

33. Ray PD, Huang BW, Tsuji Y. Reactive oxygen species (ROS) homeostasis and redox regulation in cellular signaling. Cell Signal. 2012; 24: 981-90.

34. Chen PH, Tsai CC, Lin YC, Ko YC, Yang YH, Shieh TY, et al. Ingredients contribute to variation in production of reactive oxygen species by areca quid. J Toxicol Environ Health A. 2006; 69: 1055-69.

35. Lin CY, Pan TS, Ting CC, Liang SS, Huang SH, Liu HY, et al. Cytochrome p450 metabolism of betel quid-derived compounds: implications for the development of prevention strategies for oral and pharyngeal cancers. ScientificWorldJournal. 2013; 2013: 618032.

36. Illeperuma RP, Kim DK, Park YJ, Son HK, Kim JY, Kim J, et al. Areca nut exposure increases secretion of tumor-promoting cytokines in gingival fibroblasts that trigger DNA damage in oral keratinocytes. Int J Cancer. 2015; 137: 2545-57.

37. Yen $\mathrm{CY}$, Lin MH, Liu SY, Chiang WF, Hsieh WF, Cheng YC, et al. Arecoline-mediated inhibition of AMP-activated protein kinase through reactive oxygen species is required for apoptosis induction. Oral Oncol. 2011; 47: 345-51.

38. Shih YT, Chen PS, Wu CH, Tseng YT, Wu YC, Lo YC. Arecoline, a major alkaloid of the areca nut, causes neurotoxicity through enhancement of oxidative stress and suppression of the antioxidant protective system. Free Radic Biol Med. 2010; 49: 1471-9.

39. Hung TC, Huang LW, Su SJ, Hsieh BS, Cheng HL, Hu YC, et al. Hemeoxygenase-1 expression in response to arecoline-induced oxidative stress in human umbilical vein endothelial cells. Int J Cardiol. 2011; 151: $187-94$.

40. Chang LY, Wan HC, Lai YL, Chou IC, Chen YT, Hung SL. Areca nut extracts increased the expression of cyclooxygenase-2, prostaglandin E2 and interleukin-1alpha in human immune cells via oxidative stress. Arch Oral Biol. 2013; 58: 1523-31.

41. Chang MC, Wu HL, Lee JJ, Lee PH, Chang HH, Hahn LJ, et al. The induction of prostaglandin E2 production, interleukin-6 production, cell cycle arrest, and cytotoxicity in primary oral keratinocytes and $\mathrm{KB}$ cancer cells by areca nut ingredients is differentially regulated by MEK/ERK activation. J Biol Chem. 2004; 279: 50676-83.

42. Chang MC, Chen $\mathrm{YJ}$, Chang $\mathrm{HH}$, Chan $\mathrm{CP}$, Yeh $\mathrm{CY}$, Wang $\mathrm{YL}$, et al. Areca nut components affect $\mathrm{COX}-2$, cyclin $\mathrm{B} 1 / \mathrm{cdc} 25 \mathrm{C}$ and keratin expression, PGE2 production in keratinocyte is related to reactive oxygen species, CYP1A1, Src, EGFR and Ras signaling. PLoS One. 2014; 9: e101959.

43. Hsieh YP, Wu KJ, Chen HM, Deng YT. Arecoline activates latent transforming growth factor beta1 via mitochondrial reactive oxygen species in buccal fibroblasts: Suppression by epigallocatechin-3-gallate. J Formos Med Assoc. 2018; 117: 527-34.

44. Telagi N, Ahmed Mujib BR, Kulkarni PG, Naik R. The master switch: Comparative study of mast cell in oral epithelial dysplasia, oral submucous fibrosis and oral squamous cells carcinoma and their association with inflammation and angiogenesis. J Oral Maxillofac Pathol. 2015; 19: 25-9.

45. Lai KC, Lee TC. Genetic damage in cultured human keratinocytes stressed by long-term exposure to areca nut extracts. Mutat Res. 2006; 599: 66-75.

46. Tsai YS, Lee KW, Huang JL, Liu YS, Juo SH, Kuo WR, et al. Arecoline, a major alkaloid of areca nut, inhibits p53, represses DNA repair, and triggers DNA damage response in human epithelial cells. Toxicology. 2008; 249: 230-7.

47. Huang JL, Lu HH, Lu YN, Hung PS, Lin YJ, Lin CC, et al. Enhancement of the genotoxicity of benzo[a]pyrene by arecoline through suppression of DNA repair in HEp-2 cells. Toxicol In Vitro. 2016; 33: 80-7.

48. Panigrahi GB, Rao AR. Study of the genotoxicity of the total aqueous extract of betel nut and its tannin. Carcinogenesis. 1986; 7: 37-9.

49. Wu M, Xing G, Qi X, Feng C, Liu M, Gong L, et al. Assessment of the mutagenic potential of arecoline in gpt delta transgenic mice. Mutat Res. 2012; 748: 65-9

50. Joshi MS, Verma Y, Gautam AK, Shivgotra VK, Parmar G, Kumar S. Assessment of genetic damage among chewers of mixture containing mainly areca nut and tobacco. Asia Pac J Public Health. 2011; 23: 852-60.
51. Stich HF, Stich $\mathrm{W}$. Chromosome-damaging activity of saliva of betel nut and tobacco chewers. Cancer Lett. 1982; 15: 193-202.

52. Joshi MS, Verma Y, Gautam AK, Parmar G, Lakkad BC, Kumar S. Cytogenetic alterations in buccal mucosa cells of chewers of areca nut and tobacco. Arch Oral Biol. 2011; 56: 63-7.

53. Tseng SK, Chang MC, Su CY, Chi LY, Chang JZ, Tseng WY, et al. Arecoline induced cell cycle arrest, apoptosis, and cytotoxicity to human endothelial cells. Clin Oral Investig. 2012; 16: 1267-73.

54. Ullah M, Cox S, Kelly E, Boadle R, Zoellner H. Arecoline is cytotoxic for human endothelial cells. J Oral Pathol Med. 2014; 43: 761-9.

55. Lu SY, Chang KW, Liu CJ, Tseng YH, Lu HH, Lee SY, et al. Ripe areca nut extract induces G1 phase arrests and senescence-associated phenotypes in normal human oral keratinocyte. Carcinogenesis. 2006; 27: 1273-84.

56. Lee PH, Chang MC, Chang WH, Wang TM, Wang YJ, Hahn LJ, et al. Prolonged exposure to arecoline arrested human KB epithelial cell growth: regulatory mechanisms of cell cycle and apoptosis. Toxicology. 2006; 220: $81-9$

57. Lu HH, Liu CJ, Liu TY, Kao SY, Lin SC, Chang KW. Areca-treated fibroblasts enhance tumorigenesis of oral epithelial cells. J Dent Res. 2008; 87: 1069-74.

58. Ho WH, Lee YY, Chang LY, Chen YT, Liu TY, Hung SL. Effects of areca nut extract on the apoptosis pathways in human neutrophils. J Periodontal Res. 2010; 45: 412-20.

59. Chang MC, Chan CP, Wang WT, Chang BE, Lee JJ, Tseng SK, et al. Toxicity of areca nut ingredients: activation of CHK1/CHK2, induction of cell cycle arrest, and regulation of MMP-9 and TIMPs production in SAS epithelial cells. Head Neck. 2013; 35: 1295-302.

60. Patil S, Rao RS, Raj AT. Dual role of autophagy in oral cancer. J Int Oral Health. 2015; 7: i-ii.

61. White E. The role for autophagy in cancer. J Clin Invest. 2015; 125: 42-6.

62. Lin MH, Liu YC, Liu SY, Chen FC, Yang PJ, Li GH, et al. Clathrin-mediated endocytosis is required for ANE 30-100K-induced autophagy. J Oral Pathol Med. 2018; 47: 25-31.

63. Yen CY, Chiang WF, Liu SY, Lin CC, Liao KA, Lin CY, et al. Impacts of autophagy-inducing ingredient of areca nut on tumor cells. PLoS One. 2015; 10: $\mathrm{e} 0128011$.

64. Ji WT, Lee CI, Chen JY, Cheng YP, Yang SR, Chen JH, et al. Areca nut extract induces pyknotic necrosis in serum-starved oral cells via increasing reactive oxygen species and inhibiting GSK3beta: an implication for cytopathic effects in betel quid chewers. PLoS One. 2013; 8: e63295.

65. Lu HH, Kao SY, Liu TY, Liu ST, Huang WP, Chang KW, et al. Areca nut extract induced oxidative stress and upregulated hypoxia inducing factor leading to autophagy in oral cancer cells. Autophagy. 2010; 6: 725-37.

66. Xu Z, Huang CM, Shao Z, Zhao XP, Wang M, Yan TL, et al. Autophagy induced by areca nut extract contributes to decreasing cisplatin toxicity in oral squamous cell carcinoma cells: roles of reactive oxygen species/AMPK signaling. Int J Mol Sci. 2017; 18

67. Chen YJ, Liao CT, Chen PJ, Lee LY, Li YC, Chen IH, et al. Downregulation of Ches1 and other novel genes in oral cancer cells chronically exposed to areca nut extract. Head Neck. 2011; 33: 257-66.

68. Ji WT, Yang SR, Chen JY, Cheng YP, Lee YR, Chiang MK, et al. Arecoline down-regulates levels of p21 and p27 through the reactive oxygen species/mTOR complex 1 pathway and may contribute to oral squamous cell carcinoma. Cancer Sci. 2012; 103: 1221-9.

69. Movafagh S, Crook S, Vo K. Regulation of hypoxia-inducible factor-1a by reactive oxygen species: new development in and old debate. J Cell Biochem. 2015; 116: 696-703.

70. Bredell MG, Ernst J, El-Kochairi I, Dahlem Y, Ikenberg K, Schumann DM. Current relevance of hypoxia in head and neck cancer. Oncotarget. 2016; 7: 50781-804.

71. Sharma M, Radhakrishnan R. Limited mouth opening in oral submucous fibrosis, ramifications, and remedies. J Oral Pathol Med. 2017; 46: 424-30.

72. Pereira KM, Chaves FN, Viana TS, Carvalho FS, Costa FW, Alves AP, et al. Oxygen metabolism in oral cancer: HIF and GLUTs. Oncol Lett. 2013; 6: 311-6.

73. Joseph JP, Harishankar MK, Pillai AA, Devi A. Hypoxia induced EMT: A review on the mechanism of tumor progression and metastasis in OSCC. Oral Oncol. 2018; 80: 23-32.

74. Kujan O, Shearston K, Farah CS. The role of hypoxia in oral cancer and potentially malignant disorders: a review. J Oral Pathol Med. 2017; 46: 246-52.

75. Duan $\mathrm{Y}, \mathrm{He} \mathrm{Q}$, Yue $\mathrm{K}, \mathrm{Si} \mathrm{H}$, Wang J, Zhou $\mathrm{X}$, et al. Hypoxia induced Bcl-2/Twist1 complex promotes tumor cell invasion in oral squamous cell carcinoma. Oncotarget. 2017; 8: 7729-39.

76. Ishida T, Hijioka H, Kume K, Miyawaki A, Nakamura N. Notch signaling induces EMT in OSCC cell lines in a hypoxic environment. Oncol Lett. 2013; 6: 1201-6.

77. DE Lima PO, Jorge CC, Oliveira DP, Pereira MC. Hypoxia condition and prognosis in oral squamous cell carcinoma. Anticancer Res. 2014; 34: 605-12.

78. Zhang Z, Han H, Rong Y, Zhu K, Zhu Z, Tang Z, et al. Hypoxia potentiates gemcitabine-induced stemness in pancreatic cancer cells through AKT/Notch1 signaling. J Exp Clin Cancer Res. 2018; 37: 291.

79. Takeda D, Hasegawa T, Ueha T, Iwata E, Harada R, Sakakibara A, et al. Induced pluripotent-stem-cell related genes contribute to de-differentiation in oral squamous cell carcinoma. Anticancer Res. 2017; 37: 1075-82. 
80. Ho YC, Yang SF, Lee SS, Chang YC. Regulation of hypoxia-inducible factor-1alpha in human buccal mucosal fibroblasts stimulated with arecoline. J Formos Med Assoc. 2017; 116: 484-7.

81. Tsai CH, Lee SS, Chang YC. Hypoxic regulation of plasminogen activator inhibitor-1 expression in human buccal mucosa fibroblasts stimulated with arecoline. J Oral Pathol Med. 2015; 44: 669-73.

82. Yen CY, Chiang WF, Liu SY, Cheng PC, Lee SY, Hong WZ, et al. Long-term stimulation of areca nut components results in increased chemoresistance through elevated autophagic activity. J Oral Pathol Med. 2014; 43: 91-6.

83. Ji WT, Chuang YC, Chen HP, Lee CC, Chen JY, Yang SR, et al. Areca nut extracts exert different effects in oral cancer cells depending on serum concentration: A clue to the various oral alterations in betel quid chewers. Toxicol Rep. 2014; 1: 1087-95.

84. Lee SS, Tsai $\mathrm{CH}$, Yang SF, Ho YC, Chang YC. Hypoxia inducible factor-1alpha expression in areca quid chewing-associated oral squamous cell carcinomas. Oral Dis. 2010; 16: 696-701.

85. Liu SY, Lin MH, Yang SC, Huang GC, Chang L, Chang S, et al. Areca quid chewing enhances the expression of salivary matrix metalloproteinase-9. J Formos Med Assoc. 2005; 104: 113-9.

86. Li YC, Chang JT, Chiu C, Lu YC, Li YL, Chiang $\mathrm{CH}$, et al. Areca nut contributes to oral malignancy through facilitating the conversion of cancer stem cells. Mol Carcinog. 2016; 55: 1012-23.

87. Liu YC, Lin MH, Liu SY, Chiang WF, Chen LL, Chen TC, et al. Possible mechanism of betel-quid-extract-induced expression of matrix metalloproteinase-2. J Formos Med Assoc. 2010; 109: 838-47.

88. Uehara O, Takimoto K, Morikawa T, Harada F, Takai R, Adhikari BR, et al. Upregulated expression of MMP-9 in gingival epithelial cells induced by prolonged stimulation with arecoline. Oncol Lett. 2017; 14: 1186-92.

89. Tseng YH, Chang KW, Liu CJ, Lin CY, Yang SC, Lin SC. Areca nut extract represses migration and differentiation while activating matrix metalloproteinase-9 of normal gingival epithelial cells. J Periodontal Res. 2008; 43: 490-9.

90. Lu HH, Chen LK, Cheng CY, Hung SL, Lin SC, Chang KW. Areca nut extract-treated gingival fibroblasts modulate the invasiveness of polymorphonuclear leukocytes via the production of MMP-2. J Oral Pathol Med. 2009; 38: 79-86.

91. Lee CH, Liu SY, Lin MH, Chiang WF, Chen TC, Huang WT, et al. Upregulation of matrix metalloproteinase-1 (MMP-1) expression in oral carcinomas of betel quid (BQ) users: roles of $\mathrm{BQ}$ ingredients in the acceleration of tumor cell motility through MMP-1. Arch Oral Biol. 2008; 53 : 810-8.

92. Liu SY, Liu YC, Huang WT, Huang GC, Chen TC, Lin MH. Up-regulation of matrix metalloproteinase- 8 by betel quid extract and arecoline and its role in 2D motility. Oral Oncol. 2007; 43: 1026-33.

93. Chiu CC, Chen BH, Hour TC, Chiang WF, Wu YJ, Chen CY, et al. Betel quid extract promotes oral cancer cell migration by activating a muscarinic M4 receptor-mediated signaling cascade involving SFKs and ERK1/2. Biochem Biophys Res Commun. 2010; 399: 60-5.

94. Nieto MA, Huang RY, Jackson RA, Thiery JP. Emt: 2016. Cell. 2016; 166: $21-45$

95. Sisto M, Lisi S, Ribatti D. The role of the epithelial-to-mesenchymal transition (EMT) in diseases of the salivary glands. Histochem Cell Biol. 2018; 150: 133-47.

96. Puisieux A, Brabletz T, Caramel J. Oncogenic roles of EMT-inducing transcription factors. Nat Cell Biol. 2014; 16: 488-94.

97. Scheel C, Weinberg RA. Cancer stem cells and epithelial-mesenchymal transition: concepts and molecular links. Semin Cancer Biol. 2012; 22: 396-403.

98. Fang CY, Hsia SM, Hsieh PL, Liao YW, Peng CY, Wu CZ, et al. Slug mediates myofibroblastic differentiation to promote fibrogenesis in buccal mucosa. J Cell Physiol. 2018.

99. Chang YC, Tsai CH, Lai YL, Yu CC, Chi WY, Li JJ, et al. Arecoline-induced myofibroblast transdifferentiation from human buccal mucosal fibroblasts is mediated by ZEB1. J Cell Mol Med. 2014; 18: 698-708.

100. Lee YH, Yang LC, Hu FW, Peng CY, Yu CH, Yu CC. Elevation of Twist expression by arecoline contributes to the pathogenesis of oral submucous fibrosis. J Formos Med Assoc. 2016; 115: 311-7.

101. Sume SS, Kantarci A, Lee A, Hasturk H, Trackman PC. Epithelial to mesenchymal transition in gingival overgrowth. Am J Pathol. 2010; 177: 208-18.

102. Pant I, Kumar N, Khan I, Rao SG, Kondaiah P. Role of areca nut induced TGF-beta and epithelial-mesenchymal interaction in the pathogenesis of oral submucous fibrosis. PLoS One. 2015; 10: e0129252.

103. Tseng YH, Yang CC, Lin SC, Cheng CC, Lin SH, Liu CJ, et al. Areca nut extract upregulates vimentin by activating $\mathrm{PI} 3 \mathrm{~K} / \mathrm{AKT}$ signaling in oral carcinoma. J Oral Pathol Med. 2011; 40: 160-6.

104. Tseng YH, Chang CS, Liu TY, Kao SY, Chang KW, Lin SC. Areca nut extract treatment down-regulates involucrin in normal human oral keratinocyte through P13K/AKT activation. Oral Oncol. 2007; 43: 670-9.

105. Wang TY, Peng CY, Lee SS, Chou MY, Yu CC, Chang YC. Acquisition cancer stemness, mesenchymal transdifferentiation, and chemoresistance properties by chronic exposure of oral epithelial cells to arecoline. Oncotarget. 2016; 7: 84072-81.
106. Ho CM, Hu FW, Lee SS, Shieh TM, Yu CH, Lin SS, et al. ZEB1 as an indicator of tumor recurrence for areca quid chewing-associated oral squamous cell carcinomas. J Oral Pathol Med. 2015; 44: 693-8.

107. Fan CC, Wang TY, Cheng YA, Jiang SS, Cheng CW, Lee AY, et al. Expression of E-cadherin, Twist, and p53 and their prognostic value in patients with oral squamous cell carcinoma. J Cancer Res Clin Oncol. 2013; 139: 1735-44.

108. Thangiam GS, Kondaiah P. Regulation of oxidative-stress responsive genes by arecoline in human keratinocytes. J Periodontal Res. 2009; 44: 673-82.

109. Chiu TJ, Chen CH, Chien CY, Li SH, Tsai HT, Chen YJ. High ERCC1 expression predicts cisplatin-based chemotherapy resistance and poor outcome in unresectable squamous cell carcinoma of head and neck in a betel-chewing area. J Transl Med. 2011; 9: 31.

110. Medema JP. Cancer stem cells: the challenges ahead. Nat Cell Biol. 2013; 15: 338-44

111. Sugihara E, Saya H. Complexity of cancer stem cells. Int J Cancer. 2013; 132: 1249-59.

112. Yang C, Jin K, Tong Y, Cho WC. Therapeutic potential of cancer stem cells. Med Oncol. 2015; 32: 619.

113. Chiu CC, Lee LY, Li YC, Chen YJ, Lu YC, Li YL, et al. Grp78 as a therapeutic target for refractory head-neck cancer with CD24(-)CD44(+) stemness phenotype. Cancer Gene Ther. 2013; 20: 606-15.

114. Li YL, Chang JT, Lee LY, Fan KH, Lu YC, Li YC, et al. GDF15 contributes to radioresistance and cancer stemness of head and neck cancer by regulating cellular reactive oxygen species via a SMAD-associated signaling pathway. Oncotarget. 2017; 8: 1508-28.

115. Lee SS, Tsai CH, Yu CC, Chang YC. Elevated snail expression mediates tumor progression in areca quid chewing-associated oral squamous cell carcinoma via reactive oxygen species. PLoS One. 2013; 8: e67985.

116. Lin CY, Chen WH, Liao CT, Chen IH, Chiu CC, Wang HM, et al. Positive association of glucose-regulated protein 78 during oral cancer progression and the prognostic value in oral precancerous lesions. Head Neck. 2010; 32: $1028-39$.

117. Yang TL, Wang CP, Ko JY, Lin CF, Lou PJ. Association of tumor satellite distance with prognosis and contralateral neck recurrence of tongue squamous cell carcinoma. Head Neck. 2008; 30: 631-8. 